\title{
An Overview Study on College English from the Perspective of Curriculum-Based Political and Virtuous Awareness
}

\author{
Yinjuan Song \\ College of Preparatory Education, Qinghai Minzu University, Xining 810000, China
}

\begin{abstract}
The paper searches all the key papers about College English from the perspective of Curriculum-Based Political and Virtuous Awareness. The aim of this research is studying on the current situation, tendency, and the shortcomings in the present study. It shows that: In the past two years, the number of the study is comparably small, but it was increasing. The researchers mainly focus on non-material studies rather than empirical studies. The research contents are teachers, textbooks, managements, policies, and teaching practices (aims, methods, contents, and evaluations). The problems of these studies are lacking relevant researches, monotonous research methods, insufficient coverage of research contents, etc.
\end{abstract}

Keywords: College English, Curriculum -Based Political and Virtuous Awareness, Chinese history, Holistic education.

\section{Introduction}

Xi Jinping emphasizes that teenagers are the hope of a nation and the key point of their education is to foster the right ideology[1]. The basic task of education is to foster virtue. Being an obvious way, scholars attach great importance to the ideological and political course. However, as a compulsory course of higher education stage, College English contains abundant ideological and political resources, which subconsciously affects the cultivation of students' thought, ability, and knowledge. The paper searches all the key papers about College English from the perspective of Curriculum-Based Political and Virtuous Awareness. The aim of this research is studying on the current situation, tendency, and the shortcomings in the present study, which helps to reach the goal of fostering virtue and holistic education.

\section{The Research Tendency of College English from the Perspective of Curriculum-Based Political and Virtuous Awareness}

The nation develops rapidly in the new era, the educational goal of fostering virtue becomes a research hotspot. To investigate the current situation, tendency and the shortcomings of this topic, the author searches all the key papers from CNKI with the key words (College English; Curriculum -Based Political and Virtuous Awareness; Holistic education). The result is 27 papers. The update time is on Feb. $2^{\text {nd }}, 2021$

The Figure. 1 show that the main study of this topic focuses on the year of 2020 and 2021. The number is increasing steadily. That is to say, scholars place a high value on both the cultivation of students' ability and virtue. Besides, the total number of this topic is few relatively comparing with other topic. The study of College English from the perspective of Curriculum -Based Political and Virtuous Awareness has a long way to go. This topic will be studied further.

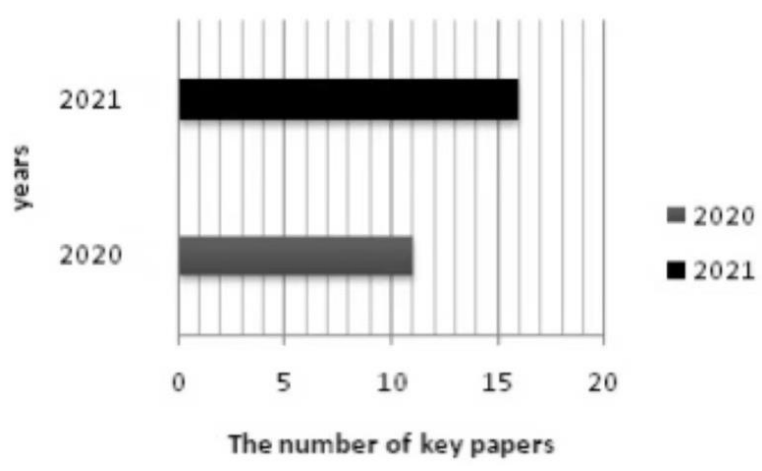

Figure 1: The Tendency of College English from the perspective of Curriculum -Based Political and Virtuous Awareness

3. The Research Methods of College English from the Perspective of Curriculum-Based Political and Virtuous Awareness

Wen Qiufang (2004) divides the research methods into empirical study and non- empirical study. Empirical study is collecting material and analyzing data scientifically and systematically to solve certain problems or certify certain arguments. Empirical study includes 3 types: qualitative research, quantitative research, and a mixed methodology of both qualitative and quantitative research. Non-empirical study is to analyze theories, reflect operations, and conclude experiences rather than problems solving[2]. The paper uses this standard to compare and analyze 27 key papers, which finds that empirical research is $19 \%$, and non-empirical research is $71 \%$. All the empirical researches are in 2021, which means scholars focus on finding the problems of studies on College English from the perspective of curriculum-based political and virtuous awareness, and exploring the effective, scientific, and objective methods. Generally speaking, researches on College English from the perspective of curriculum-based political and virtuous awareness move from theory-exploring stage to practiceexploring stage. 


\section{The Research Contents of College English from the Perspective of Curriculum-Based Political and Virtuous Awareness}

All researches could be divided into 3 types. (1) The basic task of education is to foster virtue, and the scholars put forward to macro proposals, which accounts for $29.2 \%$. (2) The scholars put forward to certain strategies for specific aspects from micro-view, which accounts for $62.5 \%$. (3) The scholars focus on policies of Curriculum-Based Political and Virtuous Awareness and analyze the spirit of documents, which accounts for $8.3 \%$.

\subsection{Macro Proposals}

The situations are as follows: (1) The scholars talk about the importance and necessity of researches on College English from the perspective of Curriculum-Based Political and Virtuous Awareness, and they offer reforming suggestions including teaching aims, textbooks, teaching methods, teaching evaluation, teacher training and course installation. (2) Liu Jing maintains that teachers should have the students-centered concept. She uses questionnaires to know the need of students from the perspective of Curriculum-Based Political and Virtuous Awareness. Meanwhile, she gives advice on cultivation of teachers, compilation of textbooks and installation of courses[3].

\subsection{Certain Strategies for Specific Aspects from Micro-view}

Researchers make efforts to find the methods of putting Curriculum -Based Political and Virtuous Awareness into practice in college English classes. (1) There are 2 main functions of the textbook which are the cultivations of students' ability and virtue. To fully perform the functions, researchers suggest that all the college English books should be re-edited and re-compiled by adding ideological and political resources. Teachers should fully make use of textbooks to cultivate students' language knowledge, language skills and virtues. (2) Fulfilling the function of management's leadership, and all the functional departments should work together to become a scientific service system to accomplish the task of fostering virtue through education. Furthermore, a panel should be assembled to establish institutional guarantee (choosing textbooks, teaching managements and evaluation). (3) From the perspective of teaching practice, researchers should blend the teaching contents and political and virtuous awareness to offer teaching suggestions about teaching designs and teaching principles for front-line teachers. (4) Teachers play the significant roles of designing teaching qualities, inheriting Chinese cultures, carrying out teaching activities. Researchers discuss the problems which may happen during the fostering virtue through education, and encourage teachers to develop their abilities of teaching students, subject quality, scientific research and obtaining information.

\subsection{Analysis of Policies and Documents}

Researches of analyzing policies and documents can be divided into 2 aspects. (1) Scholars focus on describing the process of drawing up a document, and its main content. Meanwhile, putting forward to proposals of implementing the spirit of the document. (2) Scholars deeply analyzes the problems of policies and documents and strategies of solving problems.

\section{Problems of Researches on College English from the Perspective of Curriculum-Based Political and Virtuous Awareness}

Being a newly-rising study, curriculum-based political and virtuous awareness is in the early stages, and it contains promising and wide prospects. Throughout all related researches, and the trend of this topic is rising, which brings new vigor and vitality into College English education. Moreover, it presents several new research angles of view. We can easily conclude the defects and blind spots of this topic after analyzing the research trend, methods, and contents.

\subsection{Being Short of the Amount of Research}

The figures show that researchers gradually concern studies on College English from the perspective of Curriculum-Based Political and Virtuous Awareness in the past two years. It, however, could not be ignored that the amount of related research is small, which means that researchers don't place a strong emphasis on this topic. That is to say, as a compulsory course of high education, the educational functions of College English are not fully developed.

\subsection{Monotonous Research Methods}

Throughout all the key researches, scholars emphasize the cultivation of students' comprehensive linguistic competence, intercultural communicative competence and understanding and interpreting of Chinese culture, whereas they mainly focus on non-empirical methods, and only 5 researchers use empirical methods. In other words, researchers aim at generalizing personal experiences and interpreting of educational policies. The specific methods are questionnaires, interviews, case study and text analysis. What is noteworthy is that the samples are few and have a short cycle. Thus, the results should be confirmed further.

\subsection{Insufficient Coverage of Research Contents}

The research contents are teachers, textbooks, managements, policies, and teaching practices (aims, methods, contents, and evaluations) in recent years. Scholars make effort to recognize the problems and bottlenecks which are in progress, and they also develop strategies which can deal with these unsatisfactory situations. Firstly, there is a considerable of literature on one of the certain teaching segments, especially the recommendations for innovating textbooks that accounts for $54 \%$. Being the basic guarantee of achieving teaching objectives, textbooks are valued by domestic scholars. The main weakness in their study is that they seldomly concern the subject of education which are students, learning methods and learning condition. China covers a vast territory, and the educational conditions vary greatly. Teaching practices, 
educational policies and funds tailored to local conditions are not equipped

Perfectly. The aims of College English can be divided into 3 stages: elementary, elevated, and advanced, and the specific guidance for different stage are rare. Secondly, Guiding Outline of Ideological and Political Construction in College Curriculum (2020) settle down 5 contents: Xi Jinping Thought on Socialism with Chinese Characteristics for a New Era, Core Socialist Values, The Excellent Chinese Traditional Cultures, The Constitution and the Rule of Laws, Professional Ethics[4]. However, high education of College English extremely values the Excellent Chinese Traditional Cultures, and ignoring the fostering of other contents. Finally, researchers spend much time and energy on merging Curriculum-Based Political and Virtuous Awareness with College English. Disregarding the potential of College English which is full of political and virtuous resources. Being a linguistic course, College English contains Intercultural educational attributes which is not fully explored. What's more, the functions of the universal language are interpreting and understanding of Chinese Cultures and communicating with different cultures of the whole world, which is still undervalued at existing literatures.

\section{Conclusion}

This paper attempts to spot the shortcomings of the present study by comparing and analyzing literatures on College English from the perspective of Curriculum-Based Political and Virtuous Awareness. For the purpose of offering recommendations for future research. As a newly-developing research, scholars gradually place a high premium on the function of nurturing virtues within College English. Nevertheless, comparing with other research topics of College English, there exits numerous unresolved issues. Hence, the author of this paper holds that the future effort should be made as follows: (1) Empirical studies should be emphasized by using experimental methods, ethnography, class observations instead of simply summarizing personal experiences. An argument should be proved with scientifically and systematically collected data. All the samples which are plentiful should be studied with long circles to ensure the accuracy of results. (2) The scope of research contents should be enlarged to accomplish educate students all-roundly, whole-professedly and full-anticipatedly. Since scholars mainly focus on traditional Chinese cultures of teaching practices and textbooks, irrespective of other contents stated on Guiding Outline of Ideological and Political Construction in College Curriculum (2020). Let's say splendid cultures of the whole world. This situation is against the ideology of community with a shared future for mankind which is brought up by Xi Jinping. Contents stated on Guiding Outline of Ideological and Political Construction in College Curriculum (2020) are the elements which helps students' all-round development. Teachers and researchers should forge new paths for different elements at different stages. (3) As a major status of education, students should be respected to teach them in accordance with their aptitudes. Considering that different students have their own learning conditions and abilities; teachers should design classes with tailored-teaching methods and teaching contents to cultivate their curriculum-based political and virtuous awareness subconsciously. Additionally, cooperation's among universities should be built due to educational differences regionally in China. A model system which contains demonstration classes on certain internet platforms should be organized to impel managements and faculties to learn the fantastic teaching practice. (4) English is the universal language which also has intermediary role and bridge role on Belt and Road Initiative and a Community of Shared Future. At the same time, language is a carrier of spreading culture, and helps to foster cultural confidence, sense of patriotism, responsibilities as a major country and intercultural communication competence. Thus, scholars should put a high value on humanistic attribute of College English, and melt the cultivation of Curriculum-Based Political and Virtuous Awareness into every part of college English teaching. (5) The syllabus should also be treated as a significant part of College English to organize a complete practical system (top-level design, middle-level design, and lower-level design) so as to do its utmost to mobilize all capacities of different departments. Furthermore, it serves to educate whole person with qualified English competence.

\section{References}

[1] Xi Jinping (2020). Ideological and political course is the key course to carry out the fundamental task of moral education. Qiushi, vol.17.

[2] Wen Qiufang (2004). Research methods and thesis writing in applied linguistics. Beijing: Foreign Language Teaching and Research Press, p.10-13.

[3] Liu Jing (2021).An analysis of EFL learners' needs for curriculum-based political and virtuous awareness elements in College English in the context of liberal education. Media in Foreign Language Instruction, vol.3, p.24-29.

[4] Ministry of Education (2020). Guiding outline of ideological and political construction in college curriculum, no.2. 